\title{
Cross-Cultural Adaptation and Reliability Testing of Chinese Version of the Living with Medicines Questionnaire in Elderly Patients with Chronic Diseases
}

\author{
Yongli Wang (1D) \\ Janet Krska $\mathbb{D}^{3}$ \\ Beilei Lin' \\ Yongxia Mei' \\ Barbra Katusiime ${ }^{3}$ \\ Yawen Guo' \\ Zhenxiang Zhang ${ }^{\prime}{ }^{\prime}$ \\ 'School of Nursing and Health, \\ Zhengzhou University, Zhengzhou, \\ Henan, People's Republic of China; \\ ${ }^{2}$ Peking University People's Hospital, \\ Beijing, People's Republic of China; \\ ${ }^{3}$ Medway School of Pharmacy, The \\ Universities of Kent and Greenwich at \\ Medway, Chatham, Kent, UK
}

This article was published in the following Dove Press journal:

Patient Preference and Adherence

Background: The Living with Medicines Questionnaire (LMQ-3) is a reliable, valid instrument used to assess the medication-related burden of patients with chronic disease using long-term medication, but it has not been used in China.

Purpose: To translate and cross-culturally adapt the LMQ-3 into Chinese and assess its reliability and validity among elderly patients with chronic disease.

Methods: After translation and back-translation, views from an expert group and cognitive interviews with elderly persons using multiple medicines were used to ensure the cultural relevance of the LMQ-3. Then, 412 participants aged 60-92 years were recruited from three communities in Zhengzhou to complete the instrument. Item analysis, internal consistency, content validity, exploratory factor analysis (EFA) and reliability testing were performed.

Results: Item analysis identified nine items for possible removal, which were discussed with the originating team. Internal consistency testing confirmed the suitability of removing two of these items, which concurred with the views of the expert group and cognitive interviews. All other items were retained, but four were modified for clarification without changing their meaning, resulting in a 39-item instrument. EFA of this 39-item measure yielded an eightfactor model, similar to the English version. Cronbach's alpha of the Chinese version of LMQ-3 (C-LMQ-3) for elderly patients with chronic diseases was 0.855 , and alpha values for the eight domains ranged from 0.822 to 0.932 . Test-retest reliability was satisfactory, with ICC values for the eight domain scores ranging from 0.751 to 0.881 .

Conclusion: With only minor modifications compared to the English version, the 39-item C-LMQ-3 is a valid tool, with adequate reliability, which can be used to assess the medication-related burden of long-term use of multiple medicines in elderly patients in China.

Keywords: reliability, cultural adaptation, medicine burden, patient-reported outcome, multi-morbidity, Living with Medicines Questionnaire

\section{Introduction}

Chronic diseases have become a major global public health challenge. ${ }^{1}$ In 2009 , the World Health Organization (WHO) defined "multi-morbidity" as having two or more chronic diseases. ${ }^{2}$ Multi-morbidity is a common problem, mainly in the elderly, which in China is defined as $\geq 60$ years old, in contrast to many other countries which define elderly as $\geq 65$. $^{3}$ Research has shown that $67-82 \%$ of the elderly suffer from different chronic diseases. ${ }^{4,5}$ One study found the prevalence of multi-morbidity in an urban
Correspondence: Zhenxiang Zhang School of Nursing and Health, No. 100 Science Avenue, Zhengzhou, Henan, People's Republic of China

Tel +86 I33038I6666

Fax +86 37I-8656500।

Email zhangzx6666@I26.com 
community-dwelling elderly to be $49.4 \%,{ }^{6}$ while data from the China Health and Retirement Longitudinal Study showed that multi-morbidity of physical conditions increased with age and was more common in poorer regions. ${ }^{7}$

Elderly patients often need to use polypharmacy because of multiple chronic diseases. ${ }^{8}$ A study in western China showed that older people's use of medicines was higher in urban than rural areas, with $17.5 \%$ and $11.5 \%$ of residents in these areas, respectively, using five or more medicines. ${ }^{9}$ Polypharmacy increases the risk of medication-related problems, such as adverse medication events, ${ }^{10}$ decreased medication adherence, ${ }^{11}$ increased hospitalization rates, ${ }^{12}$ falls and increased mortality. ${ }^{13}$ A systematic review ${ }^{14}$ showed that medication burden is a core factor that affects a patient's beliefs about medication adherence and health status, and to some extent reflects the patient's attitude, and willingness and ability to handle medication use. ${ }^{12,15}$ Therefore, measurement of medication burden may provide an important perspective for helping to reduce these medication-related problems and improve adherence.

The Living with Medicines Questionnaire (LMQ), which is based on the patient's self-reporting experience and measures medicine-related burden in daily life, was developed and validated by Krska et al in the UK. ${ }^{16-18}$ The LMQ originated from qualitative interviews with patients diagnosed with multi-morbidity and who used multiple medications. ${ }^{19}$ There are three versions of the LMQ, and the most recent includes aspects of medicine-related burden such as general concerns, side effects, effectiveness and cost burden. ${ }^{18}$ Currently, this instrument, which is easy to use and has shown good reliability and validity, has been used in countries such as Australia, Belgium, the Netherlands, New Zealand, Qatar, and England, ${ }^{20-24}$ and has been translated into Dutch ${ }^{21}$ and Arabic. ${ }^{25}$

There are very few studies in China that report experiences of medication burden for elderly patients with multimorbidity using multiple medicines. Research studies on both multi-morbidity and the burden of medication for patients with chronic diseases tend to focus on economic aspects of treatment burden. ${ }^{26}$ Studies show that expenditure on chronic diseases can amount to around half of disposable income, ${ }^{7}$ while other research has shown that adherence varies with the chronic condition, but is related to beliefs about medicines among Chinese communities. ${ }^{27}$ Medicine burden is a different construct, and to date, no studies in China have explored the burden that medicines can have on people's daily lives, such as side effects and other interferences. ${ }^{26}$ Chinese is the most widely used first language in the world; ${ }^{28}$ however, to date, as far as we know, there is no Chinese version of the LMQ-3. Hence, we aimed to translate and undertake cross-cultural adaptation of the LMQ-3 to create a Chinese version suitable for assessing the medication burden of Chinese elderly patients with chronic diseases, and to test its reliability and validity.

\section{Methods}

\section{Measures}

Permission to use the LMQ-3 was obtained from the author (Janet Krska) under licence agreement from the University of Kent. We used the English version of the LMQ-3, which includes 41 items in eight domains: relationships with health professionals, practicalities, interferences, effectiveness, side effects, concerns, cost and autonomy, scored using a five-point scale from strongly agree to strongly disagree. Total LMQ-3 scores range from 41 to 205; higher scores indicate greater burden associated with medicine use. Katusiime et al have demonstrated that the LMQ-3 has adequate internal consistency reliability, with Cronbach's values for the eight domains ranging from 0.692 to $0.901 .^{18}$ Construct validation of the LMQ-3 showed negative associations between medicine burden and treatment satisfaction and health-related quality of life.

\section{Translation and Cross-Cultural Adaptation}

In order to ensure semantic equivalence in the process of translation, this study followed the principle of the forward-back-translation procedure. ${ }^{29,30}$ The translation and cross-cultural adaptation of the LMQ-3 was carried out in the following steps. In step 1, two bilingual independent researchers, whose mother tongue is Chinese, translated the original English version of the LMQ-3 into Chinese. The two researchers were a pharmacologist who was proficient in pharmaceutical knowledge and an expert who was proficient in English. Our research team (including one professor of nursing, two doctors of nursing and four postgraduates majoring in elderly care) compared two Chinese versions of the translation, and finally formed a forward-translated version. In step 2, a Chinese researcher of English linguistics with 2 years of study experience in an English-speaking country, and the second pharmacology professor with experience in English language and British culture translated the Chinese version back into English. Neither had seen the LMQ-3 previously. 
In step 3, a bilingual expert group (including seven experts with qualifications and experience in pharmacy, psychology and geriatric nursing) was consulted to check whether the meaning of the Chinese version and the original version of the LMQ-3 were consistent, and to assess the cultural relevance of the Chinese version according to their theoretical knowledge and practical experience. Inclusion criteria for the experts were: 1) research area including geriatric nursing, geriatric medicine, pharmacy or psychology; 2) study experience abroad or familiar with related research fields; 3 ) intermediate and higher professional technical titles plus master's degree or above; and 4) voluntary participation in this study and provision of informed consent. This expert group was asked to use a four-point scale from 1 (not relevant) to 4 (highly relevant), to evaluate the LMQ-3's item content effectiveness index (I-CVI; that is, the number of experts with a score of 3 or 4 on each item divided by the total number of experts) and scale content effectiveness index (S-CVI; that is, the number of items rated as 3 or 4 by all experts as a percentage of total items).

In step 4, face-to-face cognitive interviews were conducted with ten elderly patients with chronic diseases to evaluate the understanding of the LMQ-3. Participants were recruited from community health service institutions and confirmed to have at least two chronic diseases from their medical records. In step 5, in order to further confirm whether the problems in the cognitive interviews had been resolved, and to collect more comprehensive recommendations based on this, we used the same recruitment method in step 4 to recruit 30 elderly patients with chronic diseases to complete the questionnaire, and made final modifications to the Chinese version of the LMQ-3 based on their feedback.

Findings from steps 3, 4 and 5 were used to inform modification of the LMQ-3 to achieve cultural adaptation for the Chinese healthcare system, in conjunction with statistical analysis. Items with I-CVI and S-CVI values of $>0.78^{31}$ and $>0.80,{ }^{32}$ respectively, as judged by the expert group were accepted as indicating relevant content. Items considered for removal, in discussion with the originators of the instrument, were those which appeared to cause confusion or difficulty in cognitive interviews and/or piloting and those with an item-total correlation coefficient $<0.3 .^{32}$

\section{Questionnaire Distribution}

We estimated the required sample size based on the ratio of subjects to items, the LMQ-3 having 41 statements $(5: 1-10: 1) .{ }^{33}$ Before the survey, we recruited and systematically trained three nursing science postgraduates as research assistants to ensure that they were familiar with the purpose, process and precautions of the questionnaire. Throughout data collection, the research assistants explained the purpose and significance of the study to the participants and obtained written informed consent.

We used the following inclusion criteria: 1) aged $\geq 60$ years (according to the Law of the People's Republic of China on the Protection of the Rights and Interests of the Elderly); 2) diagnosed with at least two chronic diseases; 3) using $\geq 5$ medications for more than 3 months; and 4) willing to participate in our study and provide informed consent. Potential participants were recruited via convenience sampling in Zhengzhou from June to October 2019. Eligible participants were identified by screening residents' health records in three community health service institutions to ensure they had at least two chronic diseases. In order to avoid losing the medication experience of elderly patients who had difficulty reading, we used a mixed method to complete the questionnaire, including the respondents completing the questionnaire by themselves and using researcher-administered interviews.

For all participants, the following demographic information was collected: age, gender, educational level, marital status, monthly family income, working status, main caregivers, living status and chronic health conditions.

Telephone numbers of all participants were retained, to enable test-retest reliability to be assessed. We randomly selected 30 patients from those who fully completed the LMQ-3 and asked them to complete a second questionnaire 2 weeks after the initial survey.

\section{Statistical Analysis}

All data were entered into Microsoft Office Excel 2016 software, and IBM SPSS 21.0 was used for statistical analysis. Descriptive statistical methods were used to summarize the demographic characteristics of the participants, including number, frequency, mean and standard deviations (SDs). We used Pearson correlation analysis to estimate correlations between the items and the total score, and item-total correlations above 0.3 were considered adequate. $^{34}$

We used confirmatory factor analysis (CFA) to determine the goodness of fit of the sample data in the C-LMQ-3 model. We assessed the following criteria: 1) a root mean square error of approximation (RMSEA) of $<0.08$; 2 ) chisquared values divided by the degrees of freedom $\left(X^{2} / d f\right)$ 
between 1 and $2 ; 3$ ) the goodness-of-fit index (GFI) $>0.90$; 4) normed fit index (NFI), adjusted GFI (AGFI) and comparative fit index (CFI), all $>0.90$. If a CFA fails to fit the factor structure proposed (here the original LMQ-3), exploratory factor analysis (EFA) can be used to improve the model. ${ }^{35}$ The internal consistency reliability of the Chinese version of the LMQ-3 (C-LMQ-3) was evaluated by Cronbach's alpha, for the instrument and each domain, with $\geq 0.7$ as the minimum acceptable value. ${ }^{36,37}$ For the test-retest reliability, we measured the intra-group correlation coefficient (ICC) for both total LMQ-3 score and the eight domain scores.

The modified version was subjected to EFA, using varimax rotation to determine the structure of the $\mathrm{C}$ LMQ-3. Any items with loadings $<0.4$, similar loads on multiple factors (where the difference was $<0.2$ ), or which resulted in domains with fewer than three items were considered for removal.

\section{Ethical Considerations}

Permission to translate the LMQ-3 into Chinese and use it in this study was obtained from the original authors. This study was approved by the Zhengzhou University ethical committee in China. During the investigation, we obtained the informed consent of the head of the community service centre, all researchers and participants. We actively introduced the purpose and significance of this study to the participants, and we also assured the participants that their responses would be anonymous and personal information confidential, prior to their signing the informed consent form.

\section{Results}

\section{Translation and Adaptation of the LMQ-3}

There was a high degree of consistency between our backtranslation and the original version of the LMQ-3. Cognitive interviews and pilot testing demonstrated that some respondents had not understood some items. Clarification of the meaning of two items was achieved through consultation with the originator of the instrument, enabling slight modifications to be made to ensure understanding. One item, concerning getting medicines from the pharmacist, was considered by the expert group as unsuitable for the Chinese healthcare system, and two items within one domain were considered by all to be duplicated. The experts group also proposed some modifications to the semantics to account for differences in culture, covering 1) driving and 2) alcohol. In the context of Chinese culture, the phenomenon of driving among the elderly is unusual, and the statement was adjusted to "going out (walking, cycling, driving, etc.)“. In China, drinking alcohol is not a highly advocated behaviour, and in particular older women rarely drink. To keep this item, we modified it to "eating habits (other food, alcohol, drinks, etc.)". In order to keep two further items, it was necessary to add examples to improve understanding; therefore "social relationships" was explained as "relationship with (family, friends, colleagues)", and “difficult" was explained as "difficult (eg, taking the medication from the package, keeping in mind the precautions for medication use, etc. $)^{\text {“" }}$.

\section{Study Participants}

A total of 450 elderly patients with chronic diseases and polypharmacy were approached, of whom 412 (91.6\%) signed the consent form. All 412 fully completed the LMQ-3. The demographic and medical characteristics of the 412 respondents are shown in Table 1 . The participants ranged in age between 60 and 92 years old, and the average age was 72.95 years (SD: 7.29). Most were female $(63.3 \%)$, were unemployed $(63.8 \%)$ and had a middle school education (42.5\%). The average age of the ten cognitive interview participants was 75.2 years old (SD: 7.86), most participants were female (60\%), 30\% had a primary school education or less and $40 \%$ had a high school education or above. The average age of the 30 pilot participants was 75.0 years old (SD: 7.36), most participants were female (53.3\%), had a middle school education $(33.3 \%)$ and were unemployed $(53.3 \%)$. On average, the study sample took $8.7 \pm 2.7$ prescription medications for 3.6 \pm 1.2 chronic conditions.

\section{Item Analysis}

The total scores for the 412 valid responses were ranked from high to low. Nine items had a total correlation value $<0.3$. All were discussed with the originators of the instrument for possible removal. As it was considered essential to retain as much similarity with the original instrument as possible, only two items were removed. These were item 2: "I find getting medicines from the pharmacist difficult" and item 3: "I am satisfied with the effectiveness of my medicines", which was considered to be too similar to item 25: "My medicines live up to my expectations", which was retained. 
Table I Demographic Characteristics of Participants $(n=4 \mid 2)$

\begin{tabular}{|c|c|}
\hline Characteristics & n (\%) \\
\hline Age (years), mean $\pm S D$ & $72.95 \pm 7.294$ \\
\hline \multicolumn{2}{|l|}{ Gender } \\
\hline Male & I5I (36.7) \\
\hline Female & 261 (63.3) \\
\hline \multicolumn{2}{|l|}{ Educational level } \\
\hline Primary school or less & $110(26.7)$ \\
\hline Middle school & $175(42.5)$ \\
\hline High school & $94(22.8)$ \\
\hline College or above & $31(7.5)$ \\
\hline \multicolumn{2}{|l|}{ Employment status } \\
\hline Retired & $147(35.7)$ \\
\hline Employed & $2(0.5)$ \\
\hline Unemployed & $263(63.8)$ \\
\hline \multicolumn{2}{|l|}{ Primary caregiver } \\
\hline Spouse & $194(47.1)$ \\
\hline Child & $175(42.5)$ \\
\hline Care workers & $2(0.5)$ \\
\hline No primary caregiver & $41(10.0)$ \\
\hline \multicolumn{2}{|l|}{ Income per month (RMB) } \\
\hline$<2000$ & $137(33.3)$ \\
\hline $2000-3000$ & $108(26.2)$ \\
\hline$>3000-4000$ & $85(20.6)$ \\
\hline$>4000$ & $82(19.8)$ \\
\hline \multicolumn{2}{|l|}{ Living status } \\
\hline Lives with spouse only & $205(49.8)$ \\
\hline Lives with children only & $42(10.2)$ \\
\hline Lives with both spouse and children & $122(29.8)$ \\
\hline Lives alone & $42(10.2)$ \\
\hline \multicolumn{2}{|l|}{ Health conditions (diagnoses) } \\
\hline High blood pressure & $352(85.4)$ \\
\hline Stroke & $196(47.6)$ \\
\hline Diabetes & $239(58.0)$ \\
\hline Hyperlipidaemia & $252(6 \mid .2)$ \\
\hline Coronary heart disease & $227(55.1)$ \\
\hline Skeletal muscle diseases & $132(32.0)$ \\
\hline Other & $67(16.3)$ \\
\hline
\end{tabular}

\section{Content Validity}

Validity refers to the extent to which a scale or test measures the psychological construct intended to be measured, and content validity is an important indicator of the usefulness and relevance of items in an instrument. ${ }^{34}$ The results of content validity analysis showed that the I-CVI of item 2 and item 3 are 0.14 and 0.43 , respectively. When these two items were deleted, the overall content validity of the questionnaire was improved. Afterwards, the
Table 2 Goodness-of-Fit Indices for the LMQ-3 Factor Models

\begin{tabular}{|l|l|l|}
\hline Index & Value & Reference Standard \\
\hline RMSEA estimate & 0.084 & $<0.05$ \\
$X^{2} / d f$ & 3.913 & $\mathrm{I}-2$ \\
Goodness of fit index (GFI) & 0.730 & $>0.90$ \\
Normed-fit index (NFI) & 0.795 & $>0.90$ \\
Adjusted GFI (AGFI) & 0.687 & $>0.90$ \\
Comparative fit index (CFI) & 0.838 & $>0.90$ \\
\hline
\end{tabular}

content validity index of each item (I -CVI) was $0.86-$ 1.00 and S-CVI was 0.949 , which are above the recommended levels of 0.78 and 0.8 , respectively, hence demonstrating adequate content validity.

\section{Construct Validity}

We first performed factor model verification on the 39-item instrument, keeping the structure consistent with the original LMQ-3. The relevant verification standard results are shown in Table 2. Our estimates of the Kaiser-Meyer-Olkin (KMO) and Bartlett test showed that our data were suitable for EFA $(\mathrm{KMO}=0.833, P<0.001)$. EFA demonstrated an eight-factor model, which accounted for $73.15 \%$ of the total variance (the results are shown in Table 3 ). Thus, the analysis supports a $\mathrm{C}$ LMQ-3 with 39 items in eight domains.

\section{Reliability Analysis}

The Cronbach's alpha of our C-LMQ-3 for elderly patients with chronic diseases was 0.855 , and for the eight domains alpha ranged from $0.822-0.932$. The total C-LMQ-3 score was highly correlated between test and retest $(r=0.786)$, and the ICC values of the eight domain scores ranged from 0.751 to 0.881 , which was satisfactory. These results indicated that the C-LMQ-3 had good reliability.

\section{Scores and Responses}

Table 4 shows the descriptive statistics of our C-LMQ-3 in elderly patients with chronic disease. The data had a normal distribution, and the overall mean score of participants on the C-LMQ-3 was 113.72 with an SD of 15.88 .

\section{Discussion}

Our study shows that, having made minor modifications for cultural differences, the C-LMQ-3 is suitable for use in Chinese elderly patients with chronic disease. The modifications involved removal of two items and minor changes or additional text to a further four items. The resultant 39item C-LMQ-3 supported an eight-domain structure which 
Table 3 Factor Structure of C-LMQ-3 ${ }^{[18]}$

\begin{tabular}{|c|c|c|c|c|c|c|c|c|}
\hline \multirow[t]{2}{*}{ Item $^{[18]}$} & \multicolumn{8}{|c|}{ Derived factors } \\
\hline & Conc & Effec & Relat & Prac & Int & sideE & Auto & Cost \\
\hline $\begin{array}{l}\text { Attitudes/concern about medicine use } \alpha=0.924 \\
\text { I worry that I have to take several medicines at the same time } \\
\text { I would like more say in the brands of medicines I use } \\
\text { I feel I need more information about my medicines } \\
\text { I am concerned about possible damaging long term effects of } \\
\text { taking medicines } \\
\text { I am concerned that I am too reliant on my medicines } \\
\text { I worry that my medicines may interact with each other } \\
\text { I am concerned that my medicines interact with eating habits } \\
\text { (other food, alcohol, drinks, etc.) }\end{array}$ & $\begin{array}{l}0.880 \\
0.863 \\
0.836 \\
0.842 \\
0.694 \\
0.832 \\
0.660\end{array}$ & & & & & & & \\
\hline $\begin{array}{l}\text { Lack of effectiveness } \alpha=0.932 \\
\text { My medicines prevent my condition getting worse } \\
\text { My medicines live up to my expectations } \\
\text { My medicines allow me to live my life as I want to } \\
\text { My medicines are working } \\
\text { The side effects are worth it for the benefits I get from my } \\
\text { medicines }\end{array}$ & & $\begin{array}{l}0.781 \\
0.863 \\
0.865 \\
0.909 \\
0.912\end{array}$ & & & & & & \\
\hline $\begin{array}{l}\text { Relationships and communication about medicines } \alpha=0.926 \\
\text { I trust the judgement of my doctor(s) in choosing medicines for } \\
\text { me } \\
\text { My doctor(s) listen to my opinions about my medicines } \\
\text { My doctor(s) takes my concerns about side effects seriously } \\
\text { I get enough information about my medicines from my doctor(s) } \\
\text { The health professionals providing my care know enough about } \\
\text { me and my medicines }\end{array}$ & & & $\begin{array}{l}0.785 \\
0.814 \\
0.913 \\
0.930 \\
0.863\end{array}$ & & & & & \\
\hline $\begin{array}{l}\text { Practical difficulties } \alpha=0.853 \\
\text { I find getting my prescriptions from the doctor difficult } \\
\text { I am comfortable with the times I should take my medicines } \\
\text { I am concerned that I may forget to take my medicines } \\
\text { It is easy to keep to my medicines routine } \\
\text { I find using my medicines difficult (eg, taking the medication from } \\
\text { the package, keeping in mind the precautions for medication use, } \\
\text { etc.) } \\
\text { I have to put a lot of planning and thought into taking my } \\
\text { medicines }\end{array}$ & & & & $\begin{array}{l}0.864 \\
0.863 \\
0.729 \\
0.636 \\
0.807 \\
\\
0.606\end{array}$ & & & & \\
\hline $\begin{array}{l}\text { Interference to day-to-day life } \alpha=0.822 \\
\text { My medicines interfere with my social or leisure activities } \\
\text { My medicines interfere with my sexual life } \\
\text { Taking medicines affects my going out (walking, cycling, driving, etc.) } \\
\text { My medicines interfere with my social relationships with (family, } \\
\text { friends, colleagues) } \\
\text { Taking medicines causes me problems with daily tasks (such as } \\
\text { work, housework, hobbies) } \\
\text { My life revolves around using my medicines }\end{array}$ & & & & & $\begin{array}{l}0.721 \\
0.613 \\
0.657 \\
0.780 \\
0.786 \\
0.678\end{array}$ & & & \\
\hline $\begin{array}{l}\text { Side effects burden } \alpha=0.912 \\
\text { The side effects I get are sometimes worse than the problem for } \\
\text { which I take medicines }\end{array}$ & & & & & & 0.810 & & \\
\hline
\end{tabular}

(Continued) 
Table 3 (Continued).

\begin{tabular}{|c|c|c|c|c|c|c|c|c|}
\hline \multirow[t]{2}{*}{ Item $^{[18]}$} & \multicolumn{8}{|c|}{ Derived factors } \\
\hline & Conc & Effec & Relat & Prac & Int & sideE & Auto & Cost \\
\hline $\begin{array}{l}\text { The side effects I get from my medicines interfere with my day- } \\
\text { to-day life (eg. work, housework, sleep) } \\
\text { The side effects I get from my medicines are bothersome } \\
\text { The side effects I get from my medicines adversely affect my well- } \\
\text { being }\end{array}$ & & & & & & $\begin{array}{l}0.842 \\
0.782 \\
0.861\end{array}$ & & \\
\hline $\begin{array}{l}\text { Autonomy/control } \alpha=0.897 \\
\text { I can vary the dose of the medicines I take } \\
\text { I can choose whether or not to take my medicines } \\
\text { I can vary the times I take my medicines }\end{array}$ & & & & & & & $\begin{array}{l}0.886 \\
0.869 \\
0.884\end{array}$ & \\
\hline $\begin{array}{l}\text { Cost-related burden } \alpha=0.878 \\
\text { I worry about paying for my medicines } \\
\text { I sometimes have to choose between buying basic essentials or } \\
\text { medicines } \\
\text { I have to pay more than I can afford for my medicines }\end{array}$ & & & & & & & & $\begin{array}{l}0.807 \\
0.843 \\
0.864\end{array}$ \\
\hline Eigenvalue & 5.310 & 4.009 & 3.951 & 3.569 & 3.356 & 3.116 & 2.631 & 2.525 \\
\hline Cumulative variance & 13.773 & 24.052 & 34.183 & 43.334 & 51.939 & 59.929 & 66.676 & 73.149 \\
\hline
\end{tabular}

Notes: Katusiime B, Corlett S, Krska J. Development and validation of a revised instrument to measure burden of long-term medicines use: the Living with Medicines Questionnaire version 3. Patient Relat Outcome Meas. 2018;9:155-168. @ University of Kent, 2020, all rights reserved.

Abbreviations: C-IMQ-3, Chinese version of Living with Medicines Questionnaire 3; Conc, general concerns about medicines; Effec, lack of effectiveness; Relat, patientdoctor relationships and communication about medicines; Int, interferences with day-to-day life; Prac, practical difficulties; SideE, side effects; Cost, auto, lack of autonomy/ control over medicine use, cost-related burden.

was the same as the original English version with the exception of these two items. Cronbach's alpha values for the instrument and for the eight domains were satisfactory and adequate test-retest reliability was also demonstrated.

The modifications made to statements were to ensure clarification and did not change their original meaning. One item was removed to reduce duplication after translation, as neither our expert group nor the cognitive interview participants could distinguish between the meaning of these two items after translation into Chinese. One further item was removed because of differences in healthcare systems between England and China. In China, pharmacists play a less important role in providing patients' medication in the community, Patients mainly get related medications from doctors, but rarely get medications from pharmacists, ${ }^{38}$ and hence the item relating to pharmacists was redundant.

The mean total LMQ-3 score for our population (113.72 \pm 15.88 ) was higher than that found in a study of the general population using one or more medicines in England (91.07 $\pm 18.92),{ }^{39}$ even after removal of two items. Studies in both England $^{39}$ and New Zealand ${ }^{22}$ have found that older people perceive lower burden than younger people. Our data suggest that a high level of medicine burden exists in elderly Chinese respondents. This was confirmed by the high proportions of respondents agreeing with individual statements. For example, $14 \%$ agreed/strongly agreed that they found using their medicines difficult, compared to only 5\% in England; 59\% felt that they needed more information, compared to only $28 \%$ in England; 27\% found side effects bothersome, compared to 18\% in England; and 36\% worried about paying for medicines, compared to $27 \%$ in England. ${ }^{39}$ These findings indicate a potentially high burden, which could affect adherence and hence health outcomes. It is thus important to measure medicine-related burden in the elderly Chinese population, and the C-LMQ-3 is a potentially useful instrument for this purpose.

\section{Strengths and Limitations}

Our translation process followed international guidelines, ${ }^{28,29}$ and we also involved an expert group to assist us in ensuring that the LMQ-3 was culturally relevant. The instrument was subjected to cognitive interviews and piloting with participants who had similar characteristics to those of the target population and underwent appropriate psychometric testing. 
Table 4 Responses to Individual Statements in the C-LMQ-3 $(n=4 / 2)^{[18]}$

\begin{tabular}{|c|c|c|c|}
\hline Statements/Domains ${ }^{[18]}$ & $\begin{array}{l}\text { Agree/ } \\
\text { Strongly } \\
\text { Agree } \\
\text { N (\%) }\end{array}$ & $\begin{array}{l}\text { Neutral } \\
\text { Opinion } \\
\text { N (\%) }\end{array}$ & $\begin{array}{l}\text { Disagree/Strongly } \\
\text { Disagree N (\%) }\end{array}$ \\
\hline \multicolumn{4}{|l|}{ Practical difficulties (6 items) } \\
\hline I find getting my prescriptions from the doctor difficult & $64(15.5)$ & IOI (24.5) & $247(60.0)$ \\
\hline I am comfortable with the times I should take my medicines & $247(60.0)$ & $94(22.8)$ & $71(17.2)$ \\
\hline I am concerned that I may forget to take my medicines & $61(14.8)$ & $97(23.5)$ & $254(61.7)$ \\
\hline It is easy to keep my medicines routine & $219(53.2)$ & $130(31.6)$ & $63(15.3)$ \\
\hline $\begin{array}{l}\text { I find using my medicines difficult (eg, taking the medication from the package, } \\
\text { keeping in mind the precautions for medication use, etc.) }\end{array}$ & $58(14.1)$ & I5I (36.7) & $312(75.7)$ \\
\hline I have to put a lot of planning and thought into taking my medicines & $75(18.2)$ & $190(46.1)$ & $147(35.7)$ \\
\hline \multicolumn{4}{|l|}{ Lack of effectiveness (5 items) } \\
\hline My medicines prevent my condition getting worse & 148 (35.9) & $121(29.4)$ & $143(34.7)$ \\
\hline My medicines live up to my expectations & $162(39.3)$ & $119(28.9)$ & $|3|(3 \mid .8)$ \\
\hline My medicines allow me to live my life as I want to & $147(35.7)$ & $127(30.8)$ & $138(33.5)$ \\
\hline My medicines are working & $119(28.9)$ & $153(37.1)$ & $140(34.0)$ \\
\hline The side effects are worth it for the benefits I get from my medicines & $120(29.1)$ & $152(36.9)$ & $140(34.0)$ \\
\hline \multicolumn{4}{|l|}{ Cost-related burden ( 3 items) } \\
\hline I worry about paying for my medicines & $227(55.1)$ & $36(8.7)$ & $149(36.1)$ \\
\hline I sometimes have to choose between buying basic essentials or medicines & $185(44.9)$ & $127(30.8)$ & $100(24.3)$ \\
\hline I have to pay more than I can afford for my medicines & $209(50.7)$ & $59(14.3)$ & $144(35.0)$ \\
\hline \multicolumn{4}{|l|}{ Communication/relationships with HCPs (5 items) } \\
\hline I trust the judgement of my doctor(s) in choosing medicines for me & $279(67.7)$ & $71(17.2)$ & $62(15.1)$ \\
\hline My doctor(s) listen to my opinions about my medicines & $236(57.3)$ & $78(18.9)$ & $98(23.8)$ \\
\hline My doctor takes my concerns about side effects seriously & $182(44.2)$ & $|5|(36.7)$ & $79(19.2)$ \\
\hline I get enough information about my medicines from my doctor(s) & $176(42.7)$ & $152(36.9)$ & $84(20.4)$ \\
\hline $\begin{array}{l}\text { The health professionals providing my care know enough about me and my } \\
\text { medicines }\end{array}$ & $203(49.3)$ & $132(32)$ & 77 (18.7) \\
\hline \multicolumn{4}{|l|}{ Concerns about medicine use ( 7 items) } \\
\hline I worry that I have to take several medicines at the same time & $213(5 \mid .7)$ & $12(2.9)$ & $187(45.4)$ \\
\hline I would like more say in the brands of medicines I use & $187(35.4)$ & $43(10.4)$ & $182(44.2)$ \\
\hline I feel I need more information about my medicines & $242(58.7)$ & $24(5.8)$ & $146(35.5)$ \\
\hline I am concerned about possible damaging long-term effects of taking medicines & $242(58.7)$ & $28(6.8)$ & $142(34.3)$ \\
\hline I am concerned that I am too reliant on my medicines & $232(56.3)$ & $27(6.6)$ & $153(37.1)$ \\
\hline $\begin{array}{l}\text { I am concerned that my medicines interact with eating habits (other food, alcohol, } \\
\text { drinks, etc.) }\end{array}$ & $147(35.7)$ & $|4|(34.2)$ & $124(30.1)$ \\
\hline I worry that my medicines may interact with each other & $109(26.5)$ & $126(30.6)$ & $177(43)$ \\
\hline \multicolumn{4}{|l|}{ Side-effect-burden (4 items) } \\
\hline $\begin{array}{l}\text { The side effects I get are sometimes worse than the problems for which I take my } \\
\text { medicines }\end{array}$ & $114(27.7)$ & $126(30.6)$ & $172(41.7)$ \\
\hline The side effects that I get from my medicines interfere with my day-to-day life & $101(24.5)$ & $106(25.7)$ & $205(49.8)$ \\
\hline The side effects I get from my medicines are bothersome & III (26.9) & $115(28.0)$ & $186(45.1)$ \\
\hline The side effects I get from my medicines adversely affect my wellbeing & $108(26.2)$ & $116(28.2)$ & $188(45.6)$ \\
\hline \multicolumn{4}{|l|}{ Interference to day-to-day life (6 items) } \\
\hline My medicines interfere with my social or leisure activities & $177(42.9)$ & $126(30.6)$ & $109(26.5)$ \\
\hline Taking medicines affects my going out (walking, cycling, driving, etc.) & $193(46.8)$ & $138(33.5)$ & $81(19.7)$ \\
\hline My medicines interfere with my social relationships with (family, friends, colleagues) & $190(46.1)$ & $133(32.3)$ & $89(21.6)$ \\
\hline Taking medicines causes problems with daily tasks & $158(38.3)$ & $158(38.3)$ & $96(23.4)$ \\
\hline
\end{tabular}

(Continued) 
Table 4 (Continued).

\begin{tabular}{|l|l|l|l|}
\hline Statements/Domains ${ }^{[18]}$ & $\begin{array}{l}\text { Agree/ } \\
\text { Strongly } \\
\text { Agree } \\
\text { N (\%) }\end{array}$ & $\begin{array}{l}\text { Neutral } \\
\text { Opinion } \\
\text { N (\%) }\end{array}$ & $\begin{array}{l}\text { Disagree/Strongly } \\
\text { Disagree N (\%) }\end{array}$ \\
\hline $\begin{array}{l}\text { My medicines interfere with my sexual life } \\
\text { My life revolves around using medicines }\end{array}$ & $\begin{array}{l}109(26.5) \\
177(43.0)\end{array}$ & $\begin{array}{l}258(62.6) \\
197(47.8)\end{array}$ & $\begin{array}{l}45(10.9) \\
38(9.2)\end{array}$ \\
\hline Autonomy/control (3 items) & $226(54.9)$ & $80(19.4)$ & $106(25.7)$ \\
I can vary the dose of the medicines I take & $243(59.1)$ & $69(16.7)$ & $100(24.2)$ \\
I can choose whether or not to take my medicines & $224(54.4)$ & $87(21.1)$ & $101(24.5)$ \\
\hline I can vary the times I take my medicines & & \\
\hline
\end{tabular}

Although the cross-cultural adaptation results of the LMQ-3 were satisfactory, there are still a few limitations to be mentioned. First, we used a convenience sampling method, and the recruited participants were communitydwelling elderly patients with chronic disease from only one city in China, Zhengzhou. Hence, the potential of the C-LMQ-3 to measure the medication-related burden of people of different ages and with specific chronic diseases is unknown. Second, we did not perform criterion-related validity to assess any of the constructs of the C-LMQ-3 against other instruments. Future work could be undertaken using relevant tools to verify the criterion-related validity of the C-LMQ-3. Our sample size was sufficient to enable psychometric testing on the basis of ten responses per item; however, further qualitative work on medicine burden is needed to understand how this construct is perceived in the Chinese population.

\section{Implications for Research and Practice}

Our findings indicate that the Chinese version of the LMQ-3 is a reliable instrument which can be used to measure the medication-related burden of elderly patients with chronic disease in mainland China, although further work is required to assess known groups and criterion-related validity. The LMQ-3 scores suggest that the medication-related burden may be high in some people within this population, and hence the instrument may have various uses in practice. First, healthcare providers should pay attention to patients' medication burden level, which can be assessed using the C-LMQ-3. Second, the C-LMQ-3 may be useful as a potential screening instrument to find patients with chronic disease who need help with medicines. Third, assessing the various aspects of medication burden in elderly patients with chronic diseases during the longterm use of multiple medicines can help us to better understand the patients' daily medication experience. Fourth, future work can investigate the factors influencing the medication-related burden, which could assist in formulating novel interventions. Finally, the C-LMQ-3 can be used to assess the effectiveness of interventions, which may help to improve the adherence and health outcomes of elderly patients with chronic diseases who use polypharmacy.

\section{Conclusion}

The LMQ-3 has been translated from the English version into Chinese and cross-cultural adaptation undertaken. The tool showed good internal consistency and reliability, and the modified instrument demonstrated a similar factor structure to the original English version. While further testing is required, the C-LMQ-3 could prove to be a useful instrument within the Chinese healthcare system to assess the medication-related burden of elderly patients with chronic diseases.

\section{Acknowledgments}

We would like to thank all participants, researchers, experts and community workers for their contributions to this work.

\section{Funding}

This study was funded by Science and Technology Department of Henan Province (no. 182102310198), and the General Research Project of Humanities and Social Sciences of Henan Provincial Department of Education (no. 2018-ZZJH-547).

\section{Disclosure}

The authors report no conflicts of interest in this work. 


\section{References}

1. Bennett JE, Stevens GA, Mathers CD, et al. NCD countdown 2030: worldwide trends in non-communicable disease mortality and progress towards sustainable development goal target 3.4. Lancet. 2018;392(10152):1072-1088. doi:10.1016/S0140-6736(18)31992-5

2. World Health Organization. Global health risks: mortality and burden of disease attributable to selected major risks. World Health Organization; 2009.

3. Chun L.Re-partitioning population age group and its implications. Popul Res. 2017;41(5):16-25.

4. Salive ME. Multimorbidity in older adults. Epidemiol Rev. 2013; 35:75-83.

5. Islam MM, Valderas JM, Yen L, et al. Multimorbidity and comorbidity of chronic diseases among the senior Australians: prevalence and patterns. PLoS One. 2014;9(1):e83783. doi:10.1371/journal.pone.00 83783

6. Wang SB, D'Arcy C, Yu YQ, et al. Prevalence and patterns of multimorbidity in northeastern China: a cross-sectional study. Public Health. 2015;129(11):1539-1546. doi:10.1016/j.puhe.2015. 06.013

7. Zhao Y, Atun R, Oldenburg B, et al. Physical multimorbidity, health service use, and catastrophic health expenditure by socioeconomic groups in China: an analysis of population-based panel data. Lancet Glob Health. 2020;8(6):e840-e849. doi:10.1016/S2214-109X(20) 30127-3

8. Abdulah R, Insani WN, Destiani DP, et al. Polypharmacy leads to increased prevalence of potentially inappropriate medication in the Indonesian geriatric population visiting primary care facilities. Ther Clin Risk Manag. 2018;14:1591-1597. doi:10.2147/TCRM.S170475

9. Yang M, Lu J, Hao Q, et al. Does residing in urban or rural areas affect the incidence of polypharmacy among older adults in western China? Arch Gerontol Geriatr. 2015;60(2):328-333. doi:10.1016/j. archger.2014.11.004

10. Gnjidic D, Tinetti M, Allore HG. Assessing medication burden and polypharmacy: finding the perfect measure. Expert Rev Clin Pharmacol. 2017;10(4):345-347. doi:10.1080/17512433.2017.1301 206

11. Lai X, Zhu H, Huo X, et al. The current status and associated factors of medication compliance in the elderly undergoing polypharmacy. $J$ Chin Nurs Manag. 2016;16(12):1638-1642.

12. Ulley J, Harrop D, Ali A, et al. Deprescribing interventions and their impact on medication adherence in community-dwelling older adults with polypharmacy: a systematic review. BMC Geriatr. 2019;19 (1):15. doi:10.1186/s12877-019-1031-4

13. Hanlon JT, Zhao X, Naples JG, et al. Central nervous system medication burden and serious falls in older nursing home residents. $J \mathrm{Am}$ Geriatr Soc. 2017;65(6):1183-1189. doi:10.1111/jgs. 14759

14. Mohammed MA, Moles RJ, Chen TF. Medication-related burden and patients' lived experience with medicine: a systematic review and metasynthesis of qualitative studies. BMJ Open. 2016;6(2):e10035. doi:10.1136/bmjopen-2015-010035

15. van der Laan DM, Elders PJM, Boons CCLM, et al. The impact of cardiovascular medication use on patients' daily lives: a cross-sectional study. Int J Clin Pharm. 2018;40(2):412-420. doi:10.1007/ s11096-018-0601-4

16. Krska J, Morecroft CW, Rowe PH, et al. Measuring the impact of long-term medicines use from the patient perspective. Int $J$ Clin Pharm. 2014;36(4):675-678. doi:10.1007/s11096-014-9970-5

17. Krska J, Katusiime B, Corlett S. Validation of an instrument to measure patients' experiences of medicine use: the Living with Medicines Questionnaire. Patient Prefer Adherence. 2017;11:671-679.

18. Katusiime B, Corlett S, Krska J. Development and validation of a revised instrument to measure burden of long-term medicines use: the Living with Medicines Questionnaire version 3. Patient Relat Outcome Meas. 2018;9:155-168.
19. Krska J, Morecroft CW, Poole H, et al. Issues potentially affecting quality of life arising from long-term medicines use: a qualitative study. Int J Clin Pharm. 2013;35(6):1161-1169. doi:10.1007/s11096-013-9841-5

20. Carter SR, Bulanadi MG, Katusiime B, et al. Comprehensibly measuring patients' subjective thoughts, feelings and experiences of living with medicines: the Living with Medicines Questionnaire (LMQ). Int J Clin Pharm. 2015;37(2):424-425.

21. Wuyts J, Maesschalck J, De Wulf I, et al. Studying the impact of a medication use evaluation by the community pharmacist (Simenon): patient-reported outcome measures. Res Social Adm Pharm. 2020.

22. Tordoff JM, Brenkley C, Krska J, et al. Exploring medicines burden among adults in New Zealand: a cross-sectional survey. Patient Prefer Adherence. 2019;13:2171-2184. doi:10.2147/PPA.S231202

23. Krska J, Corlett S, Katusiime B. Complexity of medicine regimens and patient perception of medicine burden. Pharmacy. 2019;7(1):18. doi:10.3390/pharmacy7010018

24. Zidan A, Awisu A, El-Hajj MS, et al. Medication-related burden among patients with chronic disease conditions: perspectives of patients attending non-communicable disease clinics in a primary healthcare setting in Qatar. Pharmacy. 2018;6(3):85. doi:10.3390/ pharmacy6030085

25. Zidan A, Awaisu A, Hasan S, et al. The living with medicines questionnaire: translation and cultural adaptation into the Arabic context. Value Health Reg Issues. 2016;10:36-40. doi:10.1016/j.vhri.2016.07.001

26. Liu F, Liu YL, Chen Q, et al. Investigation of the affordability of chronic diseases drug use in families from three provinces in Western China. Chin J Health Policy. 2017;10(12):54-58.

27. Wei L, Champman S, Li X, et al. Beliefs about medicines and nonadherence in patients with stroke, diabetes mellitus and rheumatoid arthritis: a cross-sectional study in China. BMJ Open. 2017;7(10): e17293. doi:10.1136/bmjopen-2017-017293

28. Chen LI. Communication of chinese from the perspective of language ecology. Jianghai Acad J. 2017;4:216-221.

29. Jones PS, Lee JW, Phillips LR, et al. An adaptation of Brislin's translation model for cross-cultural research. Nurs Res. 2001;50 (5):300-304. doi:10.1097/00006199-200109000-00008

30. Sousa VD, Rojjanasrirat W. Translation, adaptation and validation of instruments or scales for use in cross-cultural health care research: a clear and user-friendly guideline. J Eval Clin Pract. 2011;17(2):268274. doi:10.1111/j.1365-2753.2010.01434.x

31. Lynn MR. Determination and quantification of content validity. Nurs Res. 1986;35(6):382-385. doi:10.1097/00006199-198611000-00017

32. Polit DF, Beck CT. The content validity index: are you sure you know what's being reported? Critique and recommendations. Res Nurs Health. 2006;29(5):489-497. doi:10.1002/nur.20147

33. Shultz KS, Whitney DJ, Zickar MJ. Measurement Theory in Action: Case Studies and Exercises. New York: Routledge; 2013.

34. Wu ML. Questionnaire Statistical Analysis Practice: SPSS Operation and Applicatio. Chongqing: Chongqing University Press; 2019.

35. Ozer ZC, Firat MZ, Bektas HA. Confirmatory and exploratory factor analysis of the caregiver quality of life index-cancer with Turkish samples. Qual Life Res. 2009;18(7):913-921. doi:10.1007/s11136-009-9503-1

36. Barbaranelli C, Lee CS, Vellone E, et al. The problem with Cronbach's Alpha: comment on Sijtsma and van der Ark (2015). Nurs Res. 2015;64 (2):140-145. doi:10.1097/NNR.0000000000000079

37. Bentler PM. Alpha, dimension-free, and model-based internal consistency reliability. Psychometrika. 2009;74(1):137-143. doi:10. 1007/s11336-008-9100-1

38. Bei L, Tianyue F, Yang Y. Discussion for the management model of long-term medication of chronic disease under the influence of "Internet + ". CHINA HEALTH INSURANCE. 2020;7:57-60. doi:10.19546/j.issn.1674-3830.2020.7.012

39. Krska J, Katusiime B, Corlett SA. Patient experiences of the burden of using medicines for long-term conditions and factors affecting burden: a cross-sectional survey. Health Soc Care Community. 2018;26(6):946-959. doi:10.1111/hsc.12624 


\section{Publish your work in this journal}

Patient Preference and Adherence is an international, peer-reviewed, open access journal that focusing on the growing importance of patient preference and adherence throughout the therapeutic continuum. Patient satisfaction, acceptability, quality of life, compliance, persistence and their role in developing new therapeutic modalities and compounds to optimize clinical outcomes for existing disease

states are major areas of interest for the journal. This journal has been accepted for indexing on PubMed Central. The manuscript management system is completely online and includes a very quick and fair peer-review system, which is all easy to use. Visit http:// www.dovepress.com/testimonials.php to read real quotes from published authors. 